\title{
Malignant Melanoma in Child with Xeroderma Pigmentosum: A Rare Case
}

\author{
Riezky Januar Pramitha, Sawitri \\ Departement of Dermatology and Venereology \\ Faculty of Medicine Universitas Airlangga/Dr. Soetomo General Academic Teaching Hospital \\ Surabaya
}

\begin{abstract}
Background: Xeroderma pigmentosum (XP) is an autosomal recessive genetic disorder characterized by photosensitivity, cutaneous pigmentary changes, and malignant tumor development at an early age. The basic defect underlying the clinical manifestations is nucleotide excision repair defect, leading to defective repair of ultraviolet (UV)-induced DNA. XP patients who are younger than 20 years of age have more than 1000-fold increased risk of developing malignant neoplasms of the skin, which commonly include squamous cell carcinoma, basal cell carcinoma, fibrosarcoma, and malignant melanoma. Malignant melanoma arises in only about 3\% of XP patients. Purpose: To report a case of malignant melanoma in a child with XP. Case: A 7-years-old girl presented with multiple hypopigmentation and hyperpigmentation macules since age of two, throughout the body, more on sun-exposed areas. The physical examination showed solitary tumor extensive ulceroproliferative surface with areas of hemorrhage and blackish pigmentation on the vertex region. Histological examination revealed a feature of nodular malignant melanoma, and the condition became worse after she underwent two cycles of chemotherapy. Discussion: Despite the rare occurrence, the nodular type of malignant melanoma in XP patients is the most aggressive and responsible for the fatal condition. Conclusion: Early detection of XP is necessary due to its fast-growing nature and high metastatic possibility as well as mortality index.
\end{abstract}

Key words: Child, xeroderma pigmentosum, cutaneous malignancies, DNA repair, malignant melanoma.

Correspondence address: Sawitri, Department of Dermatology and Venereology, Faculty of Medicine, Universitas Airlangga, Dr. Soetomo General Academic Teaching Hospital, Jl. Prof. Dr. Moestopo No. 6-8 Surabaya 60131, Indonesia. Telepon: +62315501609, e-mail: sawitri.rh@gmail.com.

\section{INTRODUCTION}

Xeroderma pigmentosum (XP) is a rare hereditary photosensitive disease governed by autosomal recessive inheritance. This is characterized by photo-hypersensitivity sun-exposed of tissues and a nearly ten thousand-fold increase in the risk of developing malignant neoplasms of the skin. Kraemer et al. in his study on qualitative frequencies of clinical abnormalities in $830 \mathrm{XP}$ patients estimated that the median age of first non-melanoma skin cancer among patients with XP was eight years, $45 \%$ of subjects was describes having basal cell carcinoma (BCC) or squamous cell carcinoma (SCC) of the skin, and malignant melanoma arised in only about $3 \%$ of patients. ${ }^{1,2,3}$

XP has been found in all continents and across all racial groups. Consistent with autosomal recessive inheritance, males and females are similarly affected. The reported incidence rate (estimates made in the 1970s) suggested an incidence in the United State of America of 1 in 250.000 and in Japan of 1 in 20.000, with rare occurrence in India. ${ }^{3}$ There are no data of such incidence in Indonesia. Recent survey analysis in Western Europe suggested an incidence of approximately 2.3 per million live birth. It more likely occurs in populations where marriages of close bloodrelatives are common. There is no sex or race predilection. $^{3,4}$

$\mathrm{XP}$ is a human genetic disease in which genetic abnormalities occur in the DNA repair process. XP cells were unable to repair DNA damage caused by UV. Therefore, this disease does not merely occur with dermatological symptoms, such as photosensitivity, pigment change, and skin cancers, but is an intractable neurological and dermatological disease. $^{2}$

There are many reviews of XP's clinical features. In about $60 \%$ of the cases, the first indicator is an extreme sensitivity to sunlight. The other $40 \%$ of cases do not show any sunburn reaction. In such cases, the first manifestation, often by two years of age, is an unusually increased number of lentigines 
(freckle-like pigmentation) in sun-exposed areas. Small hypopigmented macules are commonly seen among the lentigines and may even be the first presentation. XP is classified into eight subtypes (group A-G genetic complementation groups and a variant type $\mathrm{V}$, and every form has the various clinical feature. ${ }^{3}$

The skin of XP patients is extremely vulnerable to UV because of a congenital defect of repairability for UV-induced DNA damage. If these patients do not take appropriate protection from sunlight, they will suffer from serious photosensitivity, followed by accelerated photoaging, warty lesions, insitu melanocyte, and keratinocyte malignancy, eventually multiple basal cell carcinomas, invasive squamous cell carcinomas and melanomas. XP patients thus need to be strictly shielded from sunlight throughout their lives, and they often experience idiopathic neurodegenerative complications that markedly reduces the quality of life (QOL) for both the patients and their families. ${ }^{2,3}$

\section{CASE REPORT}

A 7-years-old girl was consulted by pediatrician because of freckles and black spots all over the body since age of two. It initially appeared over the face, and the black spots gradually involved the entire body surface. The pigmentation appeared progressively and became worse after exposure to sunlight. She also had photophobia, redness, and watery eyes since five years ago, which became worse two weeks before hospitalization.

The patient was hospitalized in the pediatric ward 3 weeks ago with a complaint of a large bump over her head. It started initially as a $2 \mathrm{~cm}$ mass one year ago, and gradually increased in size and frequently bleed on contact. The patient was born through spontaneous vaginal delivery by midwife, in aterm age of pregnancy. The birth body weight was 2600 grams, no jaundice or cyanosis and immunizations were complete for her age. Her mother was 45 years old and healthy during her pregnancy. There was history of drug or herbal medication taken during the pregnancy. She was the third child from healthy parents, and there was no history with a similar complaint in her family. There was no history of consanguinity in her family.

The physical examination showed she was pale, suffered from poor nutrition, and her body weight was less than normal. There were multiple lymph nodes enlargement in submandibular dextra, upper-mid jugular sinistra, and lower jugular sinistra. The dermatological state on region generalisata showed multiple hypopigmented and hyperpigmentation macules unsharply marginated, especially over the sun-exposed areas. A solitary tumor $25 \times 6 \times 5 \mathrm{~cm}^{3}$ in size was observed over the vertex region. The surface showed extensive ulcero-proliferative, with areas of hemorrhage and blackish pigmentation, crusting, and there is some slough and easy to bleed on contact (Figure 1).

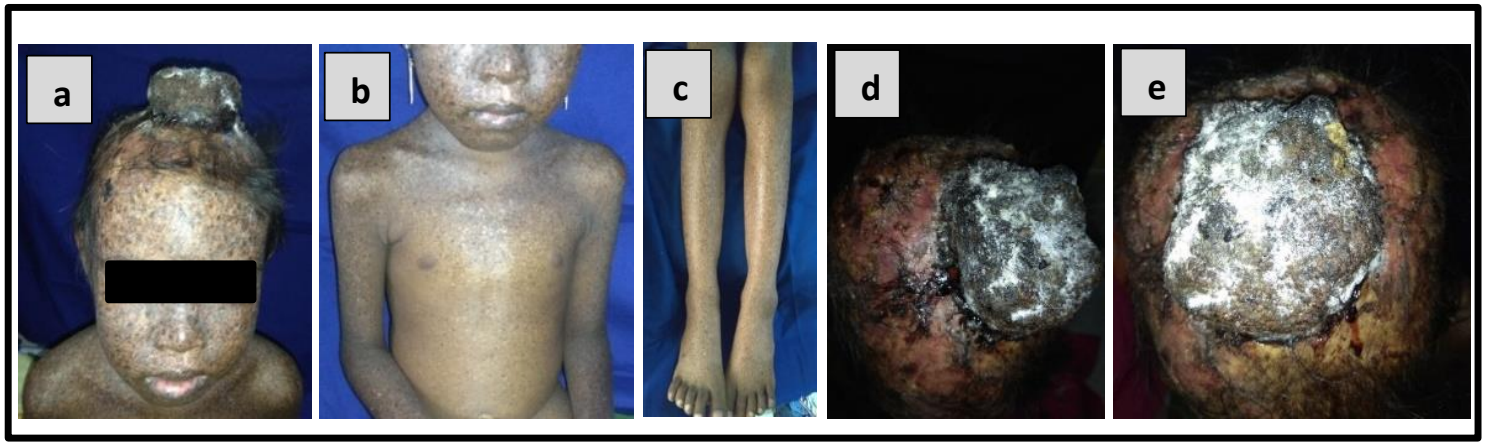

Figure 1. Dermatological state before the treatment. (a). Multiple hypopigmented and hyperpigmented macules on facial region $(b, c)$. Xeroderma pigmentosum lesion on the trunk and extremity region $(\mathrm{d}, \mathrm{e})$. Large ulcer malignant melanoma on the vertex region.

Laboratory examination revealed haemoglobin was $7.0 \mathrm{~g} / \mathrm{dL}$, white blood count $11,600 / \mathrm{mm}^{3}$, thrombocyte $622,000 / \mathrm{L}$, hematocrit $23,3 \%$. Based on the haemogram examination, ferritin was $216.2 \mu \mathrm{g} / \mathrm{L}$, iron was $18 \mathrm{Ug} / \mathrm{dl}$, and total iron binding capacity (TIBC) was $121 \mathrm{Ug} / \mathrm{dl}$. Albumin level on the blood was $3.1 \mathrm{~g} / \mathrm{dl}$. The urinalysis results were within normal limits. A radiological examination from thoracal cavity and skull were within normal limit, the multislice computed tomography (MSCT) examination with contras, showed there were multiple lymph nodes enlargement in submandibular dextra with the biggest size of $+/-1.2 \mathrm{~cm}$, upper-mid jugular sinistra $25.2 \times 6.1 \times 4.6 \mathrm{~cm}$, and $1.3 \times 1.5 \mathrm{~cm}$ in lower 
jugular sinistra (Figure 2).

Histopathological examination on HematoxylinEosin stained tissue at 100x magnification showed hyperplasia of melanocytes with melanin in the epidermis, dilated blood vessel with lymphocytes infiltration, and some macrophages that contain melanin in the dermis. This result was concordance with Xeroderma Pigmentosum. Fine Needle Aspiration Biopsy (FNAB) were performed from the mass over the vertex region at 40x magnification showing an anaplastic cell with atypical cell, pleomorphic, large and prominent nucleus, melanin in around which suitable with malignant melanoma (Figure 3).

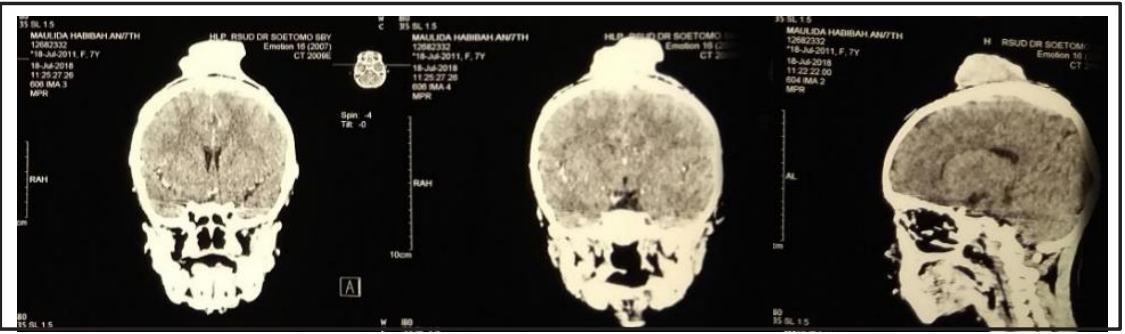

Figure 2. MSCT examination with contrast showed there were multiple lymph nodes enlargements in submandibular dextra, upper-mid jugular sinistra, and lower jugular sinistra.

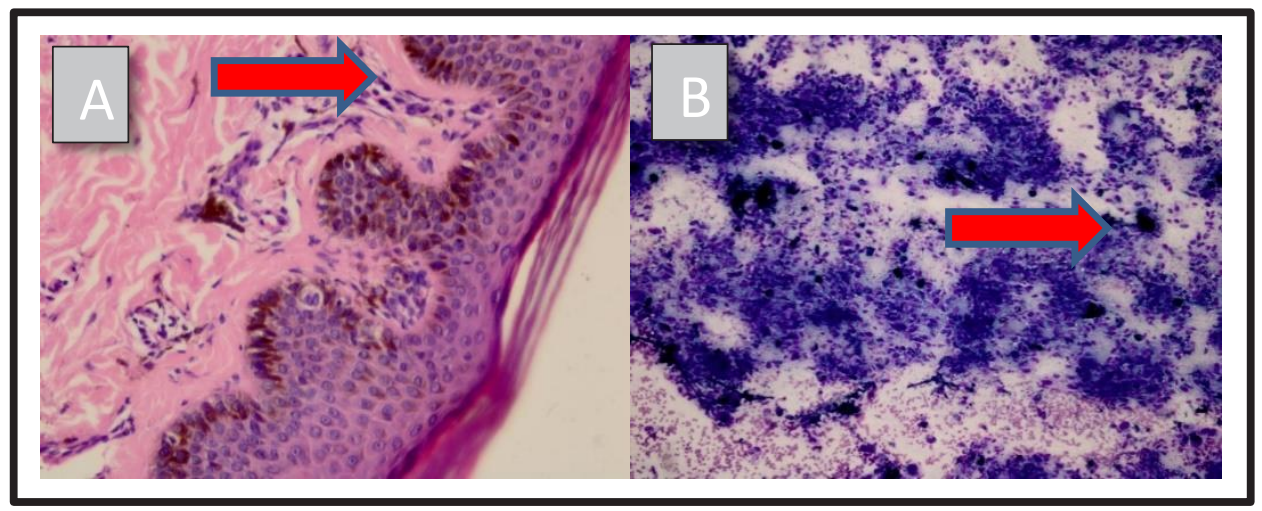

Figure 3 A. Skin Biopsy with Hematoksilin-Eosin coloring at 100x magnification, hyperplasia of melanocytes with melanin in the epidermis, dilated blood vessels with lymphocytes infiltration and some macrophages that contain melanin in the dermis were observed. B. FNAB at 40x magnification result showing an anaplastic cell with atypical cell, pleomorphic, large, and prominent nucleus.

A discussion was performed in a multidisciplinary meeting involving pediatric, oncology surgery, ophthalmology, and dermatology. According to the pediatric department, the patient was considered as having malignant melanoma and anemia, as well as poor nutrition. The patient received therapy from the pediatric department consist of PRC transfusion $160 \mathrm{ml} /$ day until the hemoglobin over 11 $\mathrm{g} / \mathrm{dl}$, children diet $1920 \mathrm{kcal}$. The oncology surgery department assessed this patient with malignant melanoma on region vertex, and there was no specific treatment. Moreover, the pediatric department decided to perform neoadjuvant chemotherapy treatment for tumor-mass reduction. This patient was given to receive three cycles of chemotherapy with cisplatin 14 $\mathrm{mg} / \mathrm{m}^{2} /$ iv drip, vinblastin $1.4 \mathrm{mg} / \mathrm{m}^{2} / \mathrm{iv}$ drip and dacarbazine $560 \mathrm{mg} / \mathrm{m}^{2} / \mathrm{iv}$ drip.

The ophthalmology department assessed this patient with moderate photosensitive and conjunctivitis and treated with cenfresh and chloramphenicol eye solution.

Moisturizing, and sunscreen creams SPF 30 were provided for XP lession. The patient and her family were educated about the disease, its prognosis and not allowed to manipulate the lesion. The patient must not be allowed to get exposed by the sun without any protection, always use sunscreen, and cover all over his body with a hat, sunglasses, and long-sleeved clothes.

After she received two cycles of chemotherapy, the condition of the patients worsened because of severe anemia and hypoalbuminemia, delaying chemotherapy. After receving two cycle of chemotherapy, the patient passed away because of the complication of the disease (hemorrhage of ulcer, severe anemia, hypoalbuminemia, and electrolyte imbalance). 


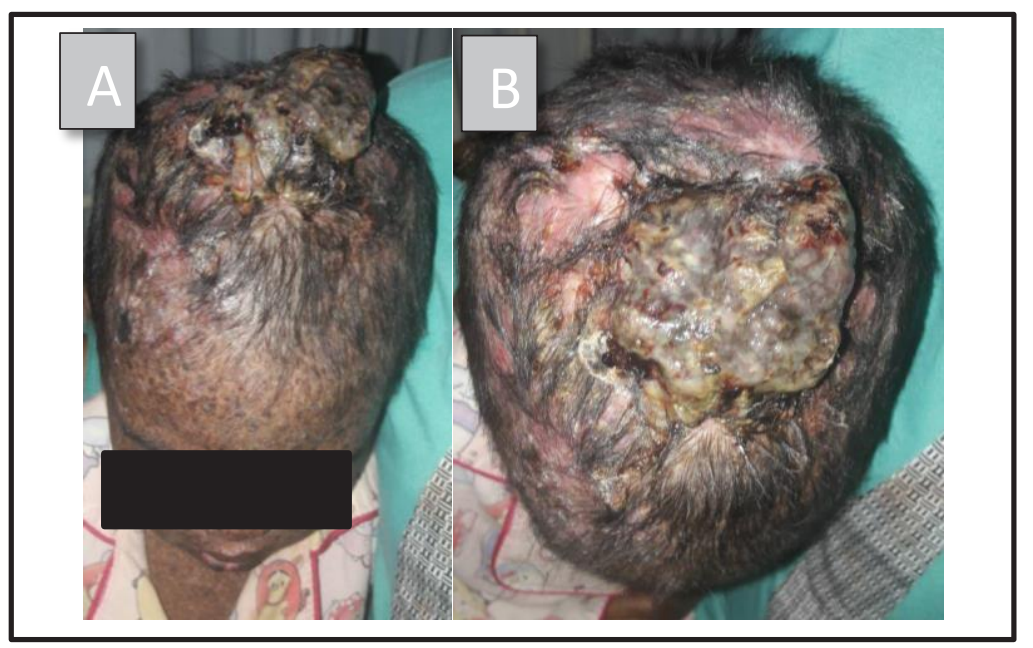

Figure 4. A and B. Large ulcer of malignant melanoma after receiving two cycles of chemotherapy. The size was smaller than before but the lesion became more ulcerative.

\section{DISCUSSION}

$\mathrm{XP}$ is a rare genetic autosomal recessive disease marked by extreme photosensitivity, hyperpigmentation and premature aging of the skin, along with the development of cutaneous and internal malignancies at an early age. ${ }^{1,2,5}$ This patient suffered from lentigines or freckles like skin pigmentation, photosensitivity, and xerosis cutis. There was marked freckling of sun-exposed areas in a child before the age of 2 years old. ${ }^{6,7}$ Photosensitivity approximately $50 \%$ of XP patients show acute sun sensitivity and also complaint about xerosis. Lentigines increase in number small hypopigmented macules giving rise to the characteristic mottled known as salt and pepper pattern of the skin. ${ }^{1,8,9}$

An individual with XP develops multiple cutaneous neoplasms at a young age. Patients younger than 20 years have a 1000-fold increase risk in the incidence of non-melanoma and melanoma skin cancer. ${ }^{3,14,15}$ XP occurs because of damage to the UVinduced DNA repair system (nucleotide excision repair/NER and translesion synthesis). XP also occurs due to mutations in any of the eight genes. These responsible genes are XPA, XPB (ERCC3), XPC, XPD (ERCC2), XPE (DDB2), XPF (ERCC4), XPG (ERCC5) and XPV (POLH). All of them are NERrelated factors (DNA damage recognition, DNA strand-opening around the lesion, excision of the DNA lesion by endonucleases, synthesis of a new complementary DNA strand, and ligation), except XPV protein, which exerts translesion DNA polymerase in the translesion synthesis system. ${ }^{1,9,10}$

UV irradiation causes photoproducts in DNA, chiefly cyclobutene-type pyrimidine dimer, and 6pyrimidine-4- pyrimidone, which further brings cell death, mutagenesis, carcinogenesis, and cellular aging. ${ }^{2,6,7}$ As a result, the accumulation of unrepaired UV induced DNA defect occurs, which either facilitates cell death, contributing to accelerated skin aging, or cellular transformation resulting in the development of malignancies. ${ }^{1,8}$ Chokri et al. in 2016 showed that the incidence of melanoma in Tunisia is relatively low $(0.5-0.7$ per 100,000 inhabitants per year). Acral Lentiginous Melanoma (ALM) was the most frequent histological subtype $(32,3 \%)$; nodular melanoma (NM) was the most aggressive and responsible for $54.8 \%$ of deaths with preferential localization on the head and neck $(\mathrm{P}<0.001)$. This is suitable for this case, which diagnosis of nodular malignant melanoma on the vertex region that started initially as a $2 \mathrm{~cm}$ mass one year ago, which has gradually increased in size and frequently bleed on contact. Victoria et al. concluded that NM is clinically distinct, and the predominant contributor to melanoma-related death (43\%). ${ }^{11}$

The newest clinical practice guideline for diagnosis of XP from the Japanese Dermatological Association in 2017 showed that definitive diagnosis can be established if there are additional examination like DNA synthesis test and genetic analysis. However, in our setting, there is a limitation to do these tests. Another literature showed that the diagnosis is based mostly on clinical findings and biopsy analysis. ${ }^{2,3,5,6}$

Early diagnosis before the development of skin tumors should be the goal. Interdisciplinary care, in conjunction with dermatologists, ophthalmologists, surgeons, and pediatricians, is necessary. Central to the care and management of patients is the strict avoidance of any exposure to ultraviolet (UV) radiation. Sunscreen with a sun protection factor of 15 or higher should be used. They should be applied at 
least 30 minutes before sun exposure. Lip moisturizers containing sun protection agents also add protection. $^{15}$

Premalignant skin lesions may be treated with cryosurgery or topical antimitotic agents. Early removal of neoplasms should be accomplished with excision, chemosurgery, or intralesional interferon- $\alpha$ (IFN- $\alpha) .{ }^{14}$ It has also been reported that imiquimod is useful for actinic keratosis and basal cell carcinoma, and IFN- $\alpha$ useful for melanoma. ${ }^{2}$. Jason et al. in 2013 showed that development combination chemotherapy regimen more effective strategies in many other solid tumors, especially in malignant melanoma. Multiple regimens were developed, notably, including CVD (cisplatin, vinblastine, dacarbazine). ${ }^{13}$ In this case, the surgeon cannot perform the excision considering the location of the lesion in the region with high vascularization that had massive bleeding risk and the general condition of the patient that made disturbance wound healing process (poor nutrition and hypoalbuminemia). For that reason, this patient received chemotherapy with multiple regiment CVD. After two cycles of chemotherapy, the smaller lesion was observed, but the general condition became worse. The patient passed away due to the complication of hemorrhage, hypoalbuminemia, and imbalance electrolyte.

\section{CONCLUSION}

$\mathrm{XP}$ is a rare genetic autosomal recessive disease that occurs because of damage on the UV-induced DNA repair system (nucleotide excision repair/NER and translesion synthesis) and a nearly ten thousandfold increase risk of developing malignant neoplasms. Despite the rare occurrence, early detection of XP is necessary due to its fast-growing nature and high metastatic possibility as well as mortality index. Severe XP with malignancy cases often require more advanced treatment, such as chemotherapy.

\section{REFERENCES}

1. Hasan S, Saeed S. Journal of pigmentary disorders xeroderma pigmentosum - a rare genodermatosis: overview of literature. Pigmentary disorder 2015; 2(12): 56-9.

2. Moriwaki S, Kanda F, Hayashi M, Yamashita D. Xeroderma pigmentosum clinical practice guidelines. J Dermatol 2017; 44(10): 1-22.

3. Kraemer KH, Lee MM, Scotto J. Xeroderma pigmentosum - cutaneous, ocular and neurological abnormalities in 830 published cases. Arch Dermatol 2011; 123: 241-50.

4. Naik SM, Shenoy AM, Rajshekar AN. Cutaneous malignancies in xeroderma pigmentosum: earlier management improves survival. Indian $\mathrm{J}$ Otolaryngol Head Neck Surg 2017; 75(2): 186-7.

5. Sethi M, Lehmann AR, Fassihi H. Xeroderma pigmentosum: a multidisciplinary approach. EMJ Dermato 2013; 1: 54-63.

6. Sugasawa K. Xeroderma pigmentosum genes: functions inside and outside DNA repair. Carcinogenesis 2018; 29(3): 455-65.

7. Brooks BP, Thompson AH, Bishop RJ, Janine A, Khan SG, Ueda T, et al. Ocular manifestations of xeroderma pigmentosum: long term follow-up highlights the role of DNA repair in protection from sun damage. Ophtalmology 2013; 120(7): 1324-36.

8. Gharote MA, Panchal HP, Anand AS, Patel AP, Parikh SK, Khatwani I V. Case report basosquamous carcinoma in xeroderma pigmentosum - a unusual case report. VJIM 2015; 18(1): 58-63.

9. Wang Y, Digiovanna JJ, Stern JB, Hornyak TJ, Raffeld M, Khan SG, et al. Evidence of ultraviolet type mutations in xeroderma pigmentosum melanomas. Porc Natl Acad Sci USA 2009; 106(15): 6279-84.

10. DiGiovanna JJ, Runger TM, Kraemer KH. Hereditary disorders of genome instability and DNA repair. In: Kang S, Amagai M, Bruckner AL, Enk AH, Margolis DJ, McMichael AJ, Orringer JS. (Eds). Fitzpatrick's Dermatology in general medicine. $9^{\text {th }}$ ed, volume 1 Mcgraw Hill; 2019. p. 2343-54.

11. Victoria, Dinesh, Ravikala R. Multiple cutaneous malignancies in a patient of xeroderma pigmentosum. J Cancer Res Ther 2011; 7(2): 205-8.

12. Chokry S, Pandey G, Bhattarai N. Myrid of histopathological features of malignancy in xeroderma pigmentosum. NepJOL 2016; 3(1): 472-5.

13. Bradford PT, Goldstein AM, Tamura D, Bradford PT, Goldstein AM, Tamura D, et al. Cancer and neurologic degeneration in xeroderma pigmentosum: long term follow-up characterises the role of DNA repair. J Med Genet 2011; 48 (3): 168-76.

14. Anand B, Kailasam S, Kumar PM, Srividhya K. Xeroderma pigmentosum: a rare case report with review of literature. J Indian Acad Oral Med Radiol 2012; 24(4): 334-7.

15. Naik SM, Shenoy AM, Rajshekar AN. Cutaneous Malignancies in xeroderma pigmentosum : earlier management improves survival. Indian J Otolaryngol Head Neck Surg 2013; 65(2): 162-7. 